\title{
Choroid Plexectomy for Hydrocephalus Management in a Pediatric Patient with a Pilocytic Astrocytoma
}

\author{
Reagan A. Collins ${ }^{1}$ Brittany $\mathrm{Tu}^{1}$ Laszlo Nagy $^{1}$ \\ ${ }^{1}$ Department of Pediatrics, Texas Tech University Health Sciences \\ Center, Lubbock, Texas, United States
}

J Neurosci Rural Pract 2021;12:804-806.

\begin{abstract}
Address for correspondence Reagan A. Collins, BA, Department of Pediatrics, Texas Tech University Health Sciences Center, SOM, 3601 4th Street, Lubbock, TX 79415, United States

(e-mail: reagan.collins@ttuhsc.edu).
\end{abstract}

\begin{abstract}
Keywords

- hydrocephalus

- choroid plexectomy

- hydranencephaly

- shunt

- cerebrospinal fluid

Choroid plexectomy is a debated surgical intervention for the treatment of hydranencephaly and chronic infected hydrocephalus. We present a case of a 2-year-old with multiple shunt revisions and hydrocephalus secondary to a pilocytic astrocytoma. He presented with new somnolence, vomiting, and abdominal distension 5 months post subtotal tumor resection, with a history of shunt revisions and infections related to his chemotherapy-induced low white blood cell count. He underwent choroid plexus coagulation and resection. Three years post choroid plexectomy, the patient continues to meet neurodevelopmental milestones and is shunt independent. While ventricular shunt placement is the most common course of treatment, choroid plexectomy should be considered as an alternative treatment of hydrocephalus secondary to other neurological disorders, especially when the patient is immunocompromised, to avoid the recurrent infections seen with shunt placement.
\end{abstract}

\section{Introduction}

Choroid plexectomy is a debated surgical intervention for treatment of hydranencephaly and chronic infected hydrocephalus. The most common surgical intervention for hydrocephalus and hydranencephaly is insertion of a ventricular shunt. However, complications associated with shunts are reported in 25.7 to $36.8 \%$ of pediatric cases within the first year of surgery. ${ }^{1}$ Choroid plexectomy was first introduced by Walter Dandy in 1918, as a way to reduce cerebrospinal fluid (CSF) overproduction and manage communicating hydrocephalus. ${ }^{2}$ Since then, choroid plexectomy has been used as an alternative to shunting, particularly in patients with multiple shunt revisions or hydranencephaly., ${ }^{3,4}$ Choroid plexectomy has varied in its success, with some suggesting the intervention leads to long-term management of hydrocephalus and eventual shunt independence, while others report poor neuropsychological outcomes and low success rates. ${ }^{2-6}$
Here, we present a case of a 2-year-old with multiple shunt revisions and hydrocephalus secondary to a pilocytic astrocytoma treated with choroid plexus coagulation and resection.

\section{Case Report}

A 2-year-old boy presented to the emergency department with new somnolence, vomiting, and abdominal distension. Past medical history included macrocephaly/hydrocephalus secondary to a pilocytic astrocytoma of the right basal ganglia and optic tract. The patient underwent subtotal tumor resection five months prior and was on carboplatin and vincristine sulfate (-Fig. 1A, B). He had multiple shunt revisions, each leading to ascites, pleural effusion, and infection related to his chemotherapy provoked low white blood cell (WBC) count.

On admission, the patient had abdominal ascites, and a shunt tap demonstrated shunt dysfunction with poor

(c) 2021. Association for Helping Neurosurgical Sick People. All rights reserved.

This is an open access article published by Thieme under the terms of the Creative Commons Attribution-NonDerivative-NonCommercial-License, permitting copying and reproduction so long as the original work is given appropriate credit. Contents may not be used for commercial purposes, or adapted, remixed, transformed or built upon. (https://creativecommons.org/ licenses/by-nc-nd/4.0/)

Thieme Medical and Scientific Publishers Pvt. Ltd., A-12, 2nd Floor, Sector 2, Noida-201301 UP, India 


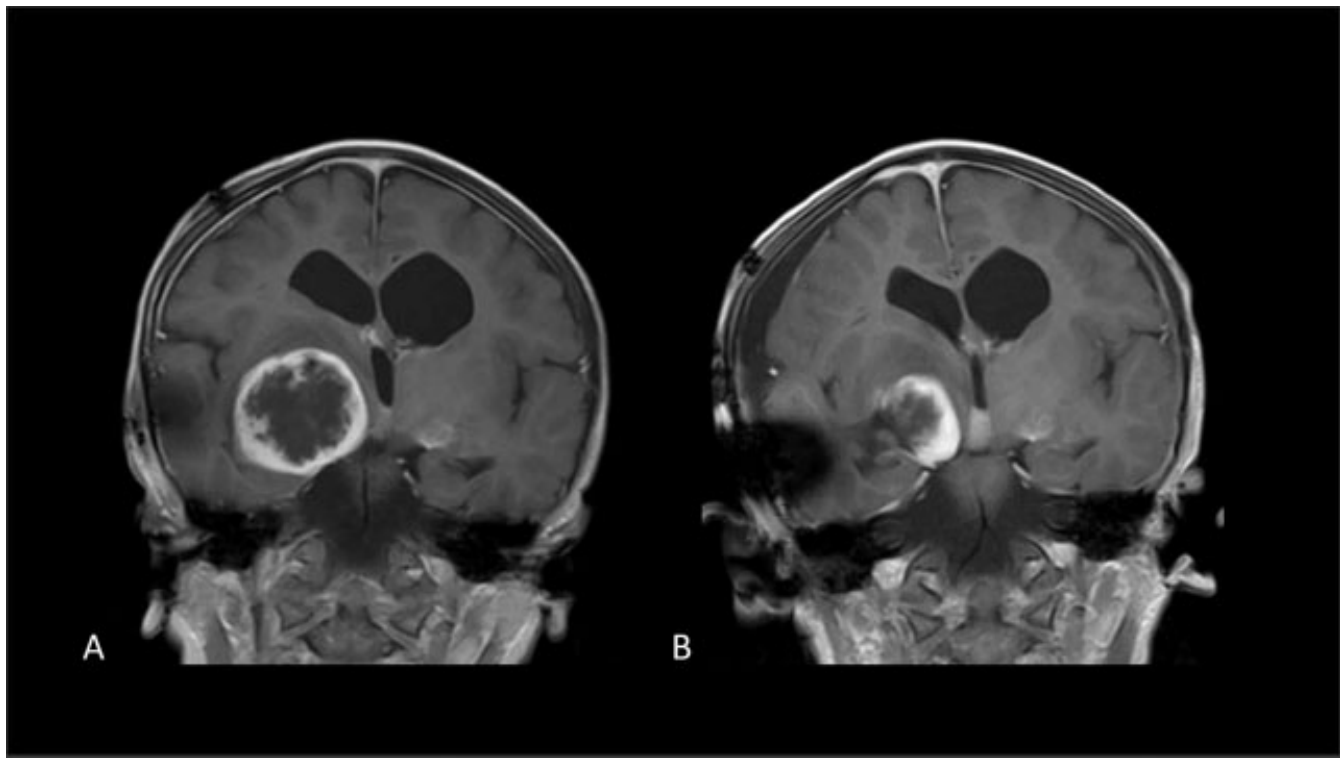

Fig. 1 Comparison of before (A) and after (B) subtotal resection of pilocytic astrocytoma on head magnetic resonance imaging.

spontaneous flow of CSF. Later that day, the patient was taken for external ventricular drain (EVD) placement and ventriculoperitoneal (VP) shunt removal. Approximately $800 \mathrm{~mL}$ of ascites were drained during the surgery, and the patient was started on vancomycin and rocephin. Following surgery, the patient was at baseline, but overnight he had an increase in right frontal swelling near the EVD site. Post admission day (PAD) 2, the right temporal EVD was open to drain at $10 \mathrm{~cm}$ with $281 \mathrm{~mL}$ of clear CSF fluid over the last 24 hours and $1+$ pitting edema to the forehead and scalp.

On PAD 3, he was taken for bilateral parietal craniotomy with choroid plexus coagulation and resection ( - Fig. 2A, B). Following coagulation surgery, he did not promptly return to baseline but remained at depressed mental status. Magnetic resonance imaging (MRI) showed stable size of the right and left temporal lesions, a slight increase in size of subdural fluid collections, and stable hydrocephalus. Post-surgical pneumocephalus was present in the frontal ventricles and subdural space. Over the next several days, his mental status improved and returned to his baseline. Repeat MRI revealed stable ventricles, and 9 days post choroid plexectomy, he was discharged home.

At his 1-week clinic follow-up, his parents reported that he seemed more alert and active, and was now walking. He was stable at his 6-week and 6-month follow-up visits. Now, 3 years post choroid plexus coagulation, he is doing well, talking, and with no major concerns. As a result of chemotherapy, the patient is currently in remission from an oncology standpoint and does not need a shunt.

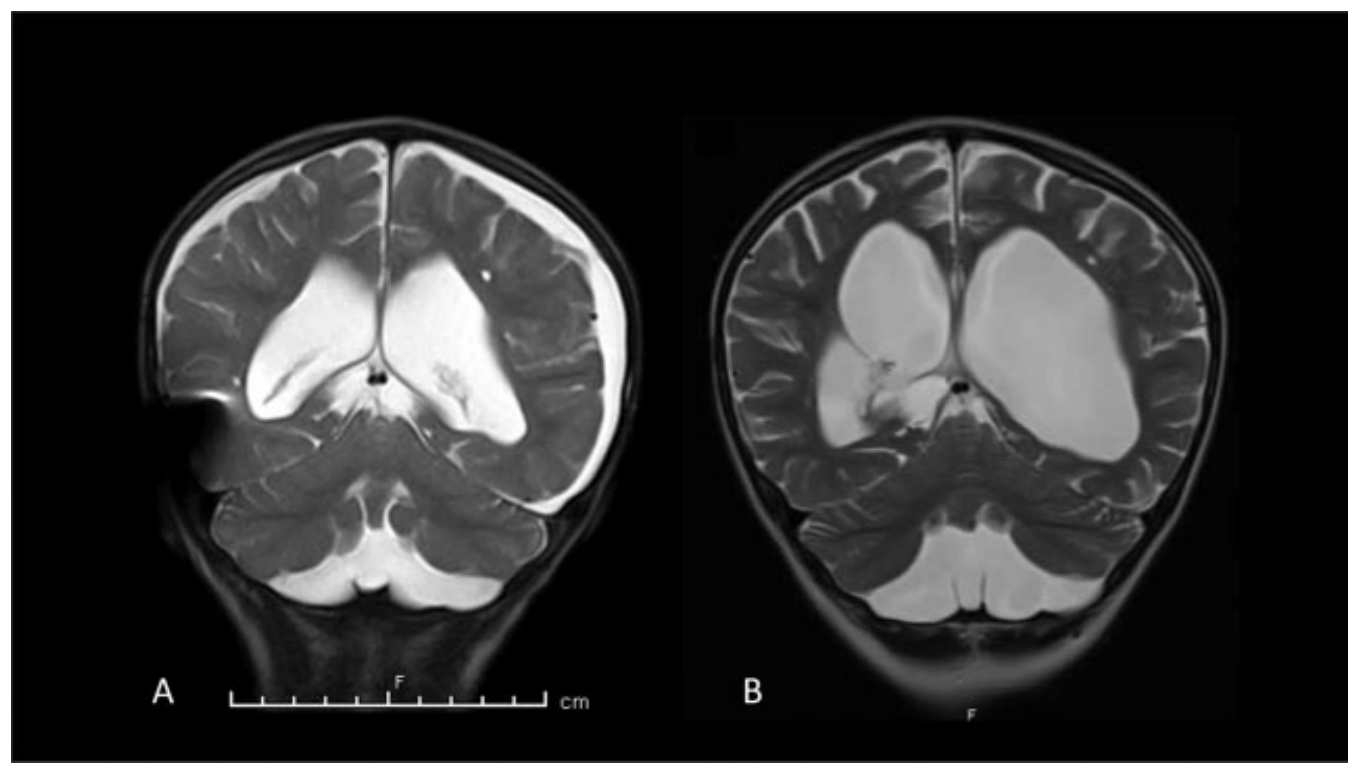

Fig. 2 Comparison of before (A) and after (B) choroid plexus coagulation on head magnetic resonance imaging. 


\section{Discussion}

Since its introduction in 1918 for the treatment of communicating hydrocephalus, ${ }^{2}$ choroid plexectomy lost its appeal with the advent of the first ventricular shunts in the 1950s. ${ }^{4}$ Plexectomy was subject to criticism into the late 20th century. Despite literature demonstrating that experimental extirpation of the choroid plexus reduces the rate of CSF formation by up to $40 \%$, failure was common and attributed to continued formation of CSF at extrachoroidal sites. ${ }^{6}$ Milhorat et al reported a case of a 3-week-old baby with severe communicating hydrocephalus, who underwent resection of the lateral ventricle choroid plexuses, followed by a VP shunt for progressive hydrocephalus 4 months later. ${ }^{6}$ Five years postoperation, the patient had comparable CSF production to patients without obstructed CSF pathways, which could explain the failure of choroid plexectomy in treating hydrocephalus. ${ }^{6}$

More recently, choroid plexectomy has been referenced for possible treatment of hydranencephaly and chronic hydrocephalus. However, the literature mainly consists of case reports and very few large, clinical cohort studies. ${ }^{4}$ In a chart review of nine pediatric patients with hydranencephaly, seven had complications following shunt placement which could be attributed to skin breakdown over hardware, CSF infection, CSF collection along the shunt tract, or disconnection of shunt. Four of the patients underwent choroid plexectomy to address the complications with shunting, with none requiring further neurosurgical operative intervention or readmission due to neurological issues. ${ }^{4}$ In a larger case series of 85 pediatric patients with shunt placement for hydrocephalus management, further operation was necessary on 27 occasions in 14 patients due to catheter obstruction. Choroid plexectomy was performed in seven cases, all of which left the shunt intact, and the patients experienced no further shunt obstruction. ${ }^{7}$ This is further supported by a case series at Kijabe Hospital Kenya, where the open choroid plexectomy cohort had the lowest 1 year mortality rate when compared to VP shunt, endoscopic choroid plexus coagulation, and palliative care patients, due to better visualization of the plexus and less hardware that could be infected or eroded. ${ }^{5}$ Additionally, recent studies have proposed the use of choroid plexus coagulation combined with third ventriculostomy to decrease the rate of shunt dependence in infants with hydrocephalus. ${ }^{8,9}$
In our case, the patient's hydrocephalus was secondary to a pilocytic astrocytoma. In addition to hydrocephalus, he was immunocompromised and undergoing chemotherapy. We suggest the consideration of choroid plexectomy as a viable alternative to shunt placement in patients with hydrocephalus secondary to other neurological diagnoses, including brain tumors. It can relieve the patient from the higher risk of shunt infections during the burden of chemotherapy, lead to shunt independence, and long-term positive outcomes. We recommend future studies focus on a larger cohort of patients with documentation of long-term outcomes.

Conflict of Interest

None declared.

\section{References}

1 Stein SC, Guo W. Have we made progress in preventing shunt failure? A critical analysis. J Neurosurg Pediatr 2008;1(01):40-47

2 Dandy WE. Extirpation of the choroid plexus of the lateral ventricles in communicating hydrocephalus. Ann Surg 1918;68 (06):569-579

3 Lapras C, Mertens P, Guilburd JN, Lapras C Jr, Pialat J, Patet JD. Choroid plexectomy for the treatment of chronic infected hydrocephalus. Childs Nerv Syst 1988;4(03):139-143

4 Wellons JC III, Tubbs RS, Leveque JC, Blount JP, Oakes WJ. Choroid plexectomy reduces neurosurgical intervention in patients with hydranencephaly. Pediatr Neurosurg 2002;36(03):148-152

5 Thiong'o GM, Ferson SS, Albright AL. Hydranencephaly treatments: retrospective case series and review of the literature. J Neurosurg Pediatr 2020;26(03):228-231

6 Milhorat TH, Hammock MK, Chien T, Davis DA. Normal rate of cerebrospinal fluid formation five years after bilateral choroid plexectomy. Case report. J Neurosurg 1976;44(06): 735-739

7 Andersson H, Carlsson CA. Plexectomy as an aid in blocked ventriculo-venous shunts. Neurochirurgia (Stuttg) 1966;9(02): 61-65

8 Fallah A, Weil AG, Juraschka K, et al. The importance of extent of choroid plexus cauterization in addition to endoscopic third ventriculostomy for infantile hydrocephalus: a retrospective North American observational study using propensity scoreadjusted analysis. J Neurosurg Pediatr 2017;20(06):503-510

9 Warf BC, Campbell JW. Combined endoscopic third ventriculostomy and choroid plexus cauterization as primary treatment of hydrocephalus for infants with myelomeningocele: long-term results of a prospective intent-to-treat study in 115 East African infants. J Neurosurg Pediatr 2008;2(05):310-316 